\title{
Chromium Substituted Cobalt Ferrites by Glycine-Nitrates Process
}

\author{
Dana Gingasu, ${ }^{1}$ Lucian Diamandescu, ${ }^{2, *}$ Ioana Mindru, ${ }^{1, *}$ Gabriela Marinescu, ${ }^{1}$ Daniela C. Culita, ${ }^{1}$ \\ Jose Maria Calderon-Moreno, ${ }^{1}$ Silviu Preda, ${ }^{1}$ Cristina Bartha, ${ }^{2,3}$ Luminita Patron ${ }^{1}$
}

\footnotetext{
1 Ilie Murgulescu Institute of Physical Chemistry, Splaiul Independentei 202, Bucharest 060021, Romania

2 National Institute of Materials Physics, 105-bis Atomistilor Street, P. O. Box MG-7, Bucharest-Magurele 077125, Romania

3 Physics Faculty, West University of Timisoara, Bd. V. Parvan 4, 300223 Timisoara, Romania

* Corresponding author's e-mail address: diamand@infim.ro, imandru@yahoo.com
}

RECEIVED: September 26, 2015 * REVISED: November 28, 2015 * ACCEPTED: December 1, 2015

THIS PAPER IS DEDICATED TO DR. SVETOZAR MUSiĆ ON THE OCCASION OF HIS 70 ${ }^{\mathrm{TH}}$ BIRTHDAY

\begin{abstract}
Chromium substituted cobalt ferrites $\left(\mathrm{CoFe}_{2-x} \mathrm{Cr}_{x} \mathrm{O}_{4}, 0 \leq x \leq 2\right)$ were synthesized through solution combustion method using glycine as fuel, named glycine-nitrates process (GNP). As evidenced by X-ray diffraction data (XRD), single cubic spinel phase was formed for all $\mathrm{CoFe}_{2-x} \mathrm{Cr}_{x} \mathrm{O}_{4}(0 \leq x \leq 2)$ series. The cubic lattice parameter $(a)$ decreases with increasing chromium content. Room temperature ${ }^{57} \mathrm{Fe}$ Mössbauer spectra revealed the $\mathrm{Fe}^{3+}$ and $\mathrm{Cr}^{3+}$ site occupancy, the local hyperfine magnetic fields and the substitution of $\mathrm{Fe}^{3+}$ by $\mathrm{Cr}^{3+}$ in the lattice. Scanning electron microscopy (SEM) showed a refinement of particle size with the increase of $\mathrm{Cr}^{3+}$ content. Magnetic measurements from $5 \mathrm{~K}$ to $120 \mathrm{~K}$ have shown a dropping in the saturation magnetization as the chromium content increases. This behaviour has been explained in terms of substitution of $\mathrm{Fe}^{3+}$ by $\mathrm{Cr}^{3+}$ in the cubic lattice of cobalt ferrite.
\end{abstract}

Keywords: glycine-nitrates process, spinel, Mössbauer spectroscopy, magnetic measurements.

\section{INTRODUCTION}

$\mathbf{N}$ ANOSCALED spinel oxides such as ferrites, chromites or chromium substituted ferrites have received considerable attention due to their applications in data storage media, telecommunications systems, electromagnetic sensors, as ferrofluids, pigments, active catalysts and, even in biomedical devices. ${ }^{[1-5]}$ The spinel ferrites exhibit two types of structures: a normal spinel structure and a partially/completely inverse structure. ${ }^{[4,6,7]}$

The cobalt ferrite $\left(\mathrm{CoFe}_{2} \mathrm{O}_{4}\right)$ is an inverse spinel in which the degree of inversion depends on the synthesis parameters and the thermal history. ${ }^{[8]}$ The cobalt chromite $\left(\mathrm{CoCr}_{2} \mathrm{O}_{4}\right)$ crystallizes in a normal spinel structure. All the $\mathrm{Co}^{2+}$ ions located in the tetrahedral positions form a diamondtype sublattice, whereas all the $\mathrm{Cr}^{3+}$ ions located in the octahedral positions build a pyrochlore-type sublattice. ${ }^{[4,9]}$

It is well known that the electric, optical and catalytic properties of the ferrites can be improved through the variation of the cations in the tetrahedral and/or the octahedral sites. ${ }^{[4,10,11]}$ For example, the substitution of $\mathrm{Fe}^{3+}$ ions with $\mathrm{Cr}^{3+}$ ions at $\mathrm{B}$ site contributes to enhancing the electrical resistivity for sensors and actuator applications. ${ }^{[10,11]}$

The synthesis method plays a very important role in the composition, the structure, the morphology and, implicitly, in the properties of the spinel ferrites/ substituted spinel ferrites. ${ }^{[12-14]}$ The critical requirements of obtaining well controlled uniformity and high-purity spinel ferrites/substituted ferrites led to the development of soft chemistry routes, such as the coprecipitation, [7] the microwave assisted route, ${ }^{[15]}$ the reverse and normal micelles, ${ }^{[16]}$ the sol-gel method, ${ }^{[17]}$ the hydrothermal route, ${ }^{[6]}$ the precursor route (the thermal decomposition of multimetallic compounds). ${ }^{[12,13,18,19]}$

One of the most interesting and attractive methods for tailoring nanosized spinel ferrites is the self-propagating combustion - the solution combustion synthesis (SCS). Discovered in 1988, during the reaction between aluminium nitrate and urea, ${ }^{[20]}$ the solution combustion 
synthesis, a simple and low cost method, uses the energy produced by the self sustained reaction between the homogeneous solution of metal nitrates as oxidizer, and urea, hydrazide, derivates of hydrazide, glycine or citric acid as fuels. The solution combustion process is characterized by high temperature, fast heating rates and very short reactions times. ${ }^{[21]}$ The structural and morphological characteristics of the final oxides depend on the nature of the fuel and the oxidizer/fuel ratio. The ratio of the nitrates to fuel in the initial mixture was calculated using propellant chemistry concepts. This ratio affects the velocity of the combustion, the temperature of the flame, and, implicitly, the features of the final oxides. ${ }^{[18,19,22-25]}$

In order to obtain nanosized chromium substituted cobalt ferrites, many research groups have used the solution combustion method with various fuels, like urea, ${ }^{[26]}$ citric acid ${ }^{[21,27]}$ etc. P. P. Hankare et al. have developed a sol-gel autocombustion method to obtain nanocrystalline $\mathrm{CoFe}_{2-x} \mathrm{Cr}_{x} \mathrm{O}_{4}$ powders $(0 \leq x \leq 2)$ using citric acid as fuel. ${ }^{[14,28,29]}$

It is the aim of this paper to report on the synthesis of nanosized chromium substituted cobalt ferrite $\mathrm{CoFe}_{2-x} \mathrm{Cr}_{x} \mathrm{O}_{4}$ $(0 \leq x \leq 2)$ through the solution combustion method using glycine as fuel; this is known as the glycine-nitrates process (GNP). The structure, morphology, site occupancy and magnetic properties of the synthesized samples are presented and discussed.

\section{EXPERIMENTAL}

\section{Reagents}

All chemicals used: the iron nitrate $\left(\mathrm{Fe}\left(\mathrm{NO}_{3}\right)_{3} \cdot 9 \mathrm{H}_{2} \mathrm{O}\right)$, the chromium nitrate $\left(\mathrm{Cr}\left(\mathrm{NO}_{3}\right)_{3} \cdot 9 \mathrm{H}_{2} \mathrm{O}\right)$, the cobalt nitrate $\left(\mathrm{Co}\left(\mathrm{NO}_{3}\right)_{2} \cdot 6 \mathrm{H}_{2} \mathrm{O}\right)$ and the glycine $\left(\mathrm{NH}_{2} \mathrm{CH}_{2} \mathrm{COOH}\right)$ were of reagent quality (Merck).

\section{Preparation of $\mathrm{CoFe}_{2-x} \mathrm{Cr}_{x} \mathrm{O}_{4}(0 \leq x \leq 2)$}

The ratio of cobalt, iron and chromium nitrates to glycine in the initial mixture was derived from the total oxidation number of the oxidizer and fuel. The "stoichiometric composition" of the redox mixture $2(-15)+1(-10)+n(+9)=0$ requires $n=4.5$. Thus, the reactants were combined in the molar proportion $2: 1: 4.5$. The reactants were mixed in an agate mortar until a honey-like homogeneous solution was formed. The hydration water from the nitrates was the only solvent. The mixed solution was placed on a heater at $250-300{ }^{\circ} \mathrm{C}$. Initially, the viscous solution melted and then it decomposed by spontaneous self-ignition, foaming and puffing, leaving behind a voluminous fluffy powder (Scheme 1).

Under complete combustion, the chemical reaction can be written as follows:

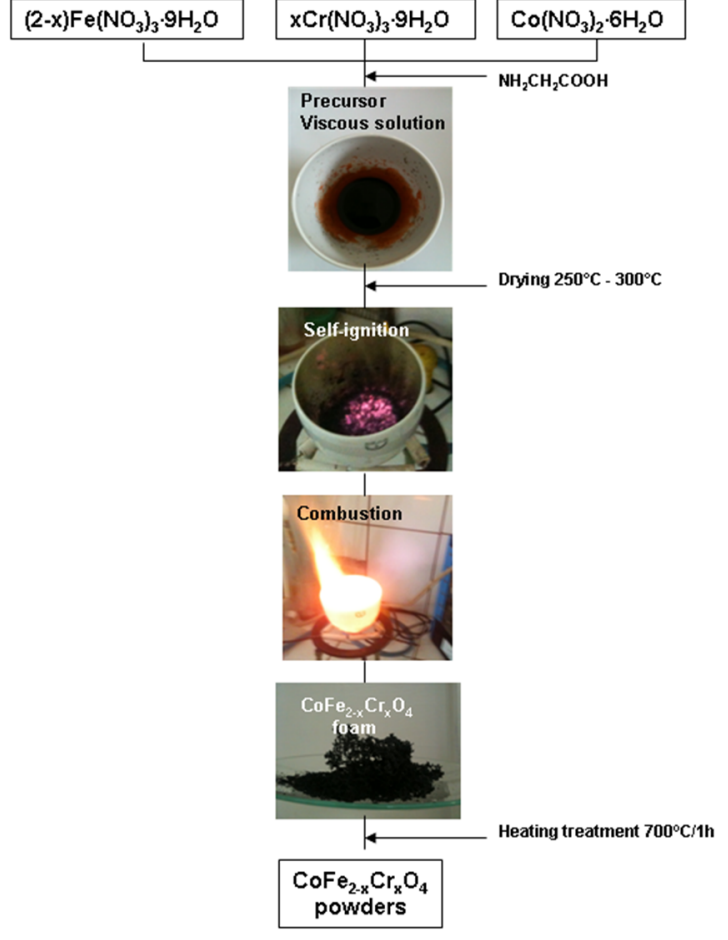

Scheme 1. The flow chart for the preparation of $\mathrm{CoFe}_{2-x} \mathrm{Cr}_{x} \mathrm{O}_{4}$ $(0 \leq x \leq 2)$ by glycine-nitrates process.

$$
\begin{gathered}
18\left(\mathrm{Fe}_{2-x} \mathrm{Cr}_{x}\right)\left(\mathrm{NO}_{3}\right)_{3}+9 \mathrm{Co}\left(\mathrm{NO}_{3}\right)_{2}+40 \mathrm{NH}_{2} \mathrm{COOH} \rightarrow \\
9 \mathrm{CoFe}_{2-x} \mathrm{Cr}_{x} \mathrm{O}_{4}+80 \mathrm{CO}_{2}+100 \mathrm{H}_{2} \mathrm{O}+56 \mathrm{~N}_{2}
\end{gathered}
$$

The powders obtained as described above were calcined at $700{ }^{\circ} \mathrm{C} / 1 \mathrm{~h}$ in order to obtain well-crystallized chromium substituted cobalt ferrites.

\section{Characterization Techniques}

$X$-ray powder diffraction data were recorded using Rigaku's Ultima IV multipurpose diffraction system. The diffractometer (operating at $40 \mathrm{kV}$ and $30 \mathrm{~mA}$ ) was set in parallel beam geometry, using $\mathrm{Cu} K_{\alpha}$ radiation $(\lambda=1.5406 \AA$ ) , CBO optics and graphite monochromator. The measurements were performed in $\vartheta-2 \vartheta$ mode, $0.02^{\circ}$ step size and $5^{\circ} \mathrm{min}^{-1}$ scan speed. Phase identification was performed using Rigaku's PDXL software, connected to ICDD PDF-2 database. The lattice constants were refined using Whole Powder Pattern Fitting (WPPF) and crystallite size was calculated by Williamson-Hall method. The microstructure of the chromium substituted cobalt ferrites was investigated by Scanning Electron Microscopy (SEM) using a FEI Quanta 3D FEG operating between 2 and $30 \mathrm{kV}$, equipped with an Energy Dispersive X-ray (EDX) spectrometer for elemental analysis. The IR spectra of the chromium substituted cobalt ferrites were recorded on $\mathrm{KBr}$ pellets with a JASCO FTIR 4100 
spectrophotometer in the $4000-400 \mathrm{~cm}^{-1}$ range. Room temperature Mössbauer measurements were performed by means of a WissEL-ICE Oxford Mössbauer cryomagnetic system and a $10 \mathrm{mCi}{ }^{57} \mathrm{Co}(\mathrm{Rh})$ source. The sample thickness was $0.7 \mathrm{mg} \mathrm{cm}^{-2}$. The magnetic measurements of heattreated chromium substituted cobalt ferrites were made using a superconducting quantum interference device (SQUID). The hysteresis loops have been obtained at three different temperatures $(5,70$ and $120 \mathrm{~K}$ ) into a magnetic field of $5 \mathrm{~T}$.

\section{RESULTS AND DISCUSSION}

The glycine-nitrates process (GNP) was applied to obtain chromium substituted cobalt ferrites $\mathrm{CoFe}_{2-x} \mathrm{Cr}_{x} \mathrm{O}_{4}(0 \leq x \leq 2)$ (Scheme 1).

The nitrates salts are preferred as "raw materials" because they can serve as nitrogen source for the synthesis and are water soluble at room temperature. The glycine is a very good, gentle fuel for the combustion reaction, being oxidized by nitrate ions. At the same time, it can act as a very good chelating agent for many metal ions. ${ }^{[18,19]}$

A. Sharma et al. ${ }^{[30]}$ describe the solution combustion reaction as a two step process with the first step corresponding to the formation of a complex compound precursor and the second step corresponding to the self-ignition.

The formation of the precursor as a single molecular compound influences the homogeneity and the stoichiometry of the final oxide. In a series of previous papers, we succeeded to isolate and characterize the precursors from GNP. ${ }^{[18,19,24,28]}$

\section{X-ray Diffraction}

The XRD patterns of all the samples $\mathrm{CoFe}_{2-x} \mathrm{Cr}_{x} \mathrm{O}_{4}(0 \leq x \leq 2)$ calcined at $700{ }^{\circ} \mathrm{C} / 1 \mathrm{~h}$ show the formation of the single

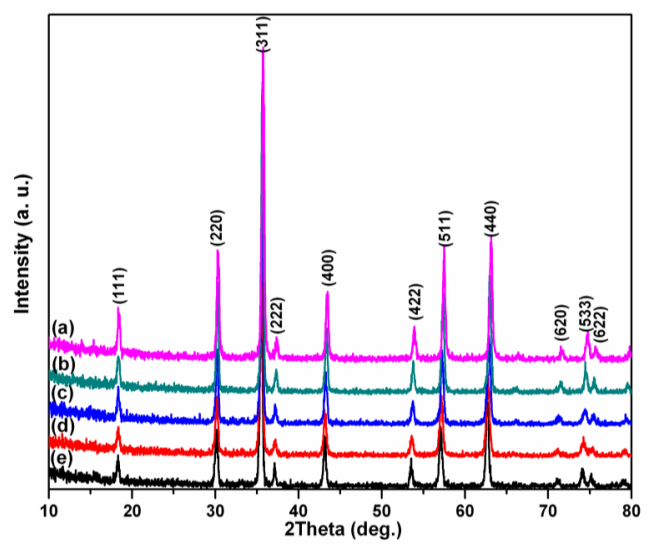

Figure 1. X-ray diffraction patterns of chromium substituted cobalt ferrite powders $\left(\mathrm{CoFe}_{2-x} \mathrm{Cr}_{x} \mathrm{O}_{4}\right)$, where $x$ is: (a) 0 ; (b) 0.5; (c) 1 ; (d) 1.5 ; and (e) 2 , calcined at $700^{\circ} \mathrm{C} / 1 \mathrm{~h}$.
Table 1. Lattice parameters and crystallite size of chromium substituted cobalt ferrite $\left(\mathrm{CoFe}_{2-x} \mathrm{Cr}_{x} \mathrm{O}_{4}\right.$ where $\left.0 \leq x \leq 2\right)$ series.

\begin{tabular}{ccc}
\hline Sample & Lattice parameter, $a, / \AA$ & Crystallite size $/ \AA$ \\
\hline $\mathrm{CoFe}_{2} \mathrm{O}_{4}$ & 8.384 & 227 \\
$\mathrm{CoFe}_{1.5} \mathrm{Cr}_{0.5} \mathrm{O}_{4}$ & 8.371 & 240 \\
$\mathrm{CoFeCrO}_{4}$ & 8.358 & 249 \\
$\mathrm{CoFe}_{0.5} \mathrm{Cr}_{1.5} \mathrm{O}_{4}$ & 8.348 & 220 \\
$\mathrm{CoCr}_{2} \mathrm{O}_{4}$ & 8.328 & 216 \\
Errors & \pm 0.003 & \pm 4 \\
\hline
\end{tabular}

phase cubic spinel structure belonging to the space group Fd3m (ICDD 022-1086 for $\mathrm{CoFe}_{2} \mathrm{O}_{4}$; ICDD 22-1084 for $\mathrm{CoCr}_{2} \mathrm{O}_{4}$ ). No additional lines corresponding to any other phase were detected (Figure 1).

The lattice parameter $a$ decreases with the increase of the $\mathrm{Cr}^{3+}$ content from $8.384 \AA$ to $8.328 \AA$ (Table 1 ). This decrease in $a$ with $x$ can be explained based on the difference in ionic radii between the larger ionic radius $\mathrm{Fe}^{3+}$ ion $(0.67 \AA)$ and the smaller ionic radius $\mathrm{Cr}^{3+}$ ion $(0.63 \AA)$. ${ }^{[14,21]}$ The average crystallite size of all the ferrite samples was $\sim 230 \AA$.

\section{Scanning Electron Microscopy}

SEM measurements emphasize a clear refinement of particle size with the increase of $\mathrm{Cr}^{3+}$ content $(x) . \mathrm{CoFe}_{2} \mathrm{O}_{4}(x=0$, Figure 2a-c), exhibits a sintered porous structure of faceted grains sized $\sim 1$ micron, while $\mathrm{CoCr}_{2} \mathrm{O}_{4}(x=2$, Figure $2 \mathrm{~d}-\mathrm{f})$, exhibits a structure of fine non-agglomerated nanoscale powder. The gradual change of the microstructure and the elemental composition in the intermediate samples containing both iron and chromium ( $x=0.5,1$ and 1.5) can be observed in Figure 3. The presence of iron seems to ease sintering and the particle growth of the ferrite powders at relatively moderate temperature. This effect can be attributed to the fact that the magnetic interaction between

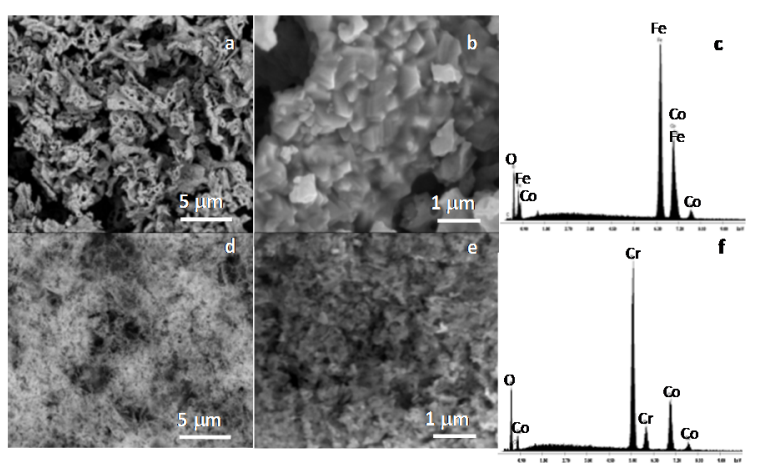

Figure 2. SEM micrographs and EDX spectra of $(a-c) \mathrm{CoFe}_{2} \mathrm{O}_{4}$; and (d-f) $\mathrm{CoCr}_{2} \mathrm{O}_{4}$. calcined at $700{ }^{\circ} \mathrm{C} / 1 \mathrm{~h}$. 


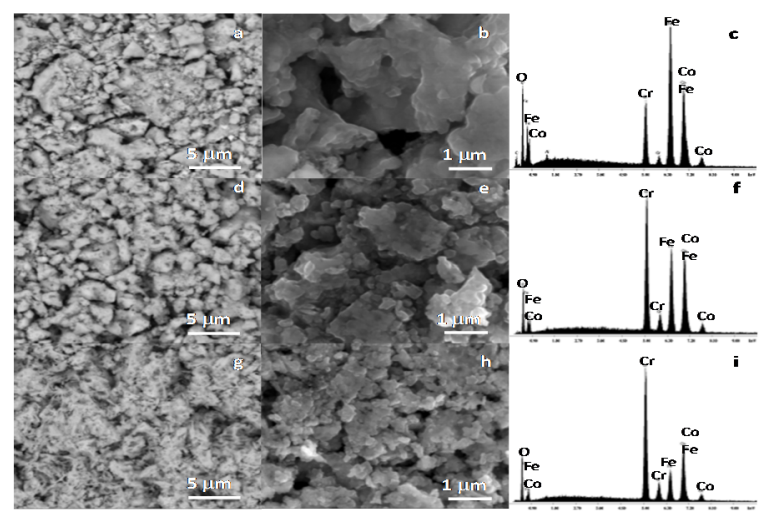

Figure 3. SEM micrographs and EDX spectra of $(a-c)$ $\mathrm{CoFe}_{1.5} \mathrm{Cr}_{0.5} \mathrm{O}_{4}$; (d-f) $\mathrm{CoFeCrO}_{4}$; (g-i) $\mathrm{CoFe}_{0.5} \mathrm{Cr}_{1.5} \mathrm{O}_{4}$, calcined at $700{ }^{\circ} \mathrm{C} / 1 \mathrm{~h}$.

crystallites can facilitate their advantageous self-alignment, promoting low temperature sintering. The effect gradually diminishes and disappears with the growth of the $\mathrm{Cr}^{3+}$ content. The same effect was previously observed in the chromium substituted copper ferrites. ${ }^{[13]}$

\section{FT-IR Spectroscopy}

The formation of the spinel structure of $\mathrm{CoFe}_{2-x} \mathrm{Cr}_{x} \mathrm{O}_{4}(0 \leq x$ $\leq 2$ ) is also supported by the FT-IR analysis. The IR spectra of all the samples are recorded in the range $4000-400 \mathrm{~cm}^{-1}$. The two very intense metal-oxygen bands observed in these IR spectra represent characteristic features of the single phase spinel ferrites (Figure 4). The higher band, $v_{1}$, in the range $615-570 \mathrm{~cm}^{-1}$, corresponds to the stretching vibrations of the metal from the tetrahedral site, $M_{\text {tetra }} \leftrightarrow 0$, whereas the lower band $\left(v_{2}\right)$, in the range $508-395 \mathrm{~cm}^{-1}$, is assigned to the octahedral metal stretching, $\mathrm{M}_{\text {octa }} \leftrightarrow \mathrm{O}$. It is well known that $\mathrm{Co}^{2+}$ and $\mathrm{Cr}^{3+}$ ions are preferentially located in the octahedral site, while $\mathrm{Fe}^{3+}$ ions can occupy both octahedral and tetrahedral sites.

In the IR spectra of the $\mathrm{CoFe}_{2-x} \mathrm{Cr}_{x} \mathrm{O}_{4}(0 \leq x \leq 2)$ samples the bands $\left(v_{1}\right)$ and $\left(v_{2}\right)$ shift towards higher frequencies with the increase of the $\mathrm{Cr}^{3+}$ content: $v_{1}$ shifts from 578 to $615 \mathrm{~cm}^{-1}$, while $v_{2}$ shifts from 395 to $508 \mathrm{~cm}^{-1}$. According to literature, the increase of the $\mathrm{Cr}^{3+}$ leads to the gradual transition from an inverted spinel structure to a normal one. ${ }^{[4,14,31,32]}$

\section{Mössbauer Spectroscopy}

Figure $5(a-d)$ shows the room temperature Mössbauer spectra of the samples $\mathrm{CoFe}_{2-x} \mathrm{Cr}_{x} \mathrm{O}_{4}(x=0 ; 0.5 ; 1.5 ; 2)$ together with the computer fit (continuous) lines, under the hypothesis of Lorentzian line shape. In order to understand the Mössbauer results we have to remember that in $\mathrm{AB}_{2} \mathrm{O}_{4}$ spinels every A-site (tetrahedral) iron ion is surrounded by 12 B-site (octahedral) next nearest neighbours and each B-site iron ion is bounded by six A-site nearest neighbours. ${ }^{[33,34]}$

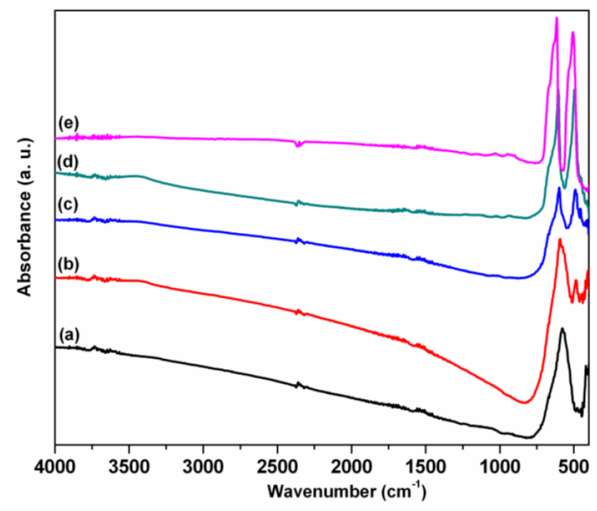

Figure 4. IR spectra of chromium substituted cobalt ferrite powders ( $\left.\mathrm{CoFe}_{2-x} \mathrm{Cr}_{x} \mathrm{O}_{4}\right)$, where $x$ is: (a) 0 ; (b) 0.5 ; (c) 1 ; (d) 1.5; and (e) 2, annealed at $700{ }^{\circ} \mathrm{C} / 1 \mathrm{~h}$.

The hyperfine parameters (isomer shift IS, quadrupole splitting $\Delta E_{\mathrm{Q}}$ and magnetic fields $H_{\mathrm{hf}}$ at the iron nucleus) for all Mössbauer spectra are listed in Table 1. In the computer fit, the line intensities were fixed at $3: 2: 1$ (theoretical values) for all magnetic sublattices, the line widths were considered equal and kept fixed for all magnetic sextets and free for the central quadrupole doublet.

At $x=0$, the Mössbauer spectrum (Figure 5a) consists of a magnetic hyperfine pattern that was deconvoluted in two sextets corresponding to $\mathrm{Fe}^{3+}$ ions in tetrahedral and octahedral sites, respectively. ${ }^{[33]}$ The site assignment, from the extent of hyperfine magnetic fields in $\mathrm{CoFe}_{2} \mathrm{O}_{4}$, is controversial in the literature. ${ }^{[33-37]}$ More recent studies consider that the IS values correlated with the structural data can be better used for site assignments in cobalt ferrite. Consequently, the sextet with lower IS $\left(\sim 0.19 \mathrm{~mm} \mathrm{~s}^{-1}\right.$, relative to $\alpha$-iron) is assigned to iron in tetrahedral sites (from inter-nuclear distance arguments) ${ }^{[35]}$ and the sextet with higher IS $\left(0.32 \mathrm{~mm} \mathrm{~s}^{-1}\right)$ corresponds to octahedral iron sites.

At $x=0.5$, the Mössbauer spectrum is rather complex (Figure $5 b$ ), showing a magnetic hyperfine pattern with large line width accompanied by a central quadrupole doublet. Taking into account the strong preference of chromium ions for octahedral sites, the probability for $\mathrm{Cr}^{3+}$ to occupy the 12 positions of $B$ sites, could be mathematically described by a binomial distribution. We have to note that the binomial (random) distribution is a pure mathematical approach to describe the unresolved structure of complex systems. In the hypothesis of random distribution of $\mathrm{Cr}^{3+}$ in octahedral positions, the best fit was obtained by considering six magnetic sublattices and a central quadrupole contribution. In Table 2, $\mathrm{B}_{n}$ denotes the relevant magnetic sublattice (spectral area $>5 \%$ ) corresponding to the presence of , $\mathrm{n}^{\prime} \mathrm{Cr}^{3+}$ ions in the $\mathrm{B}$ sites of the spinel structure. The same refinement procedure was applied for the sample at $x=1.0$ (Figure $5 \mathrm{c}$ ). The best fit was given by seven magnetic sextets in the fitting run. 


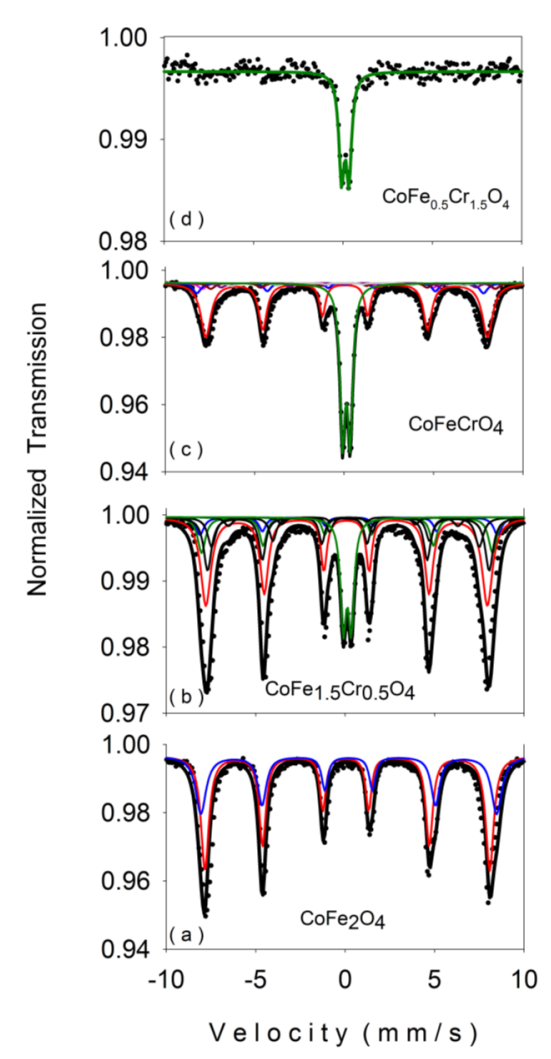

Figure 5. Mössbauer spectra of chromium substituted cobalt ferrite $\left(\mathrm{CoFe}_{2-} \mathrm{Cr}_{x} \mathrm{O}_{4}\right)$, where $x$ is: (a) 0 ; (b) 0.5; (c) 1 ; and (d) 1.5, annealed at $700^{\circ} \mathrm{C} / 1 \mathrm{~h}$.

At $x=1.5$, the Mössbauer spectrum (Figure $5 \mathrm{~d}$ ) displays a single quadrupole doublet with IS $=0.263 \mathrm{~mm} \mathrm{~s}^{-1}$ and $\Delta E_{\mathrm{Q}}=0.414 \mathrm{~mm} \mathrm{~s}^{-1}$, parameters very close in value to those at $x=0.5$ and 1.0. These values are characteristic to the $\mathrm{Fe}^{3+}$ ions. The quadrupole doublets in the spectra at $x=0.5,1.0$ and 1.5 can be associated with the contribution to the Mössbauer spectra of iron ions with very reach $\mathrm{Cr}^{3+}$ neighbouring. $\mathrm{No} \mathrm{Fe}^{2+}$ was evidenced in the analysed spectra.

\section{Magnetic Measurements}

Figure 6 displays the magnetic hysteresis loops for all chromium substituted cobalt ferrite samples calcined at $700^{\circ} \mathrm{C} / 1 \mathrm{~h}$. The magnetic parameters were determined from the individual $\mathrm{M}-\mathrm{H}$ curves and were presented in Table 3.

Table 3 clearly shows that the saturation magnetization $\left(M_{\mathrm{s}}\right)$ at $5 \mathrm{~K}$ decreases with the increase in the $\mathrm{Cr}^{3+}$ ions content from $82.34 \mathrm{emu}^{-1}$ to $42.38 \mathrm{emu} \mathrm{g}^{-1}$ in the chromium substituted cobalt ferrites. This decrease is due to the replacement of the $\mathrm{Fe}^{3+}$ ions (magnetic moment $5 \mu \mathrm{B}$ ) by the less magnetic $\mathrm{Cr}^{3+}$ ions (magnetic moment $3 \mu \mathrm{B}$ ) in the octahedral (B) sites of the ferrite lattice. This behaviour is also observed in the evolution of coercivity $\left(B_{c}\right)$; the presence of $\mathrm{Cr}^{3+}$ ions induces a decrease in the anisotropy field which in
Table 2. Mössbauer fit results for the chromium substituted cobalt ferrite samples.

\begin{tabular}{|c|c|c|c|c|}
\hline Sample & $\begin{array}{c}\mathrm{IS}^{*} / \\
\mathrm{mm} \mathrm{s}^{-1}\end{array}$ & $\begin{array}{c}\Delta E_{\mathrm{Q}} / \\
\mathrm{mm} \mathrm{s}^{-1}\end{array}$ & $\begin{array}{c}H_{\text {hf }} / \\
T\end{array}$ & $\begin{array}{l}\text { Site / phase } \\
\text { assignment }\end{array}$ \\
\hline \multirow[t]{2}{*}{$\mathrm{CoFe}_{2} \mathrm{O}_{4}$} & 0.193 & 0.057 & 48.64 & $A$ \\
\hline & 0.320 & -0.020 & 50.58 & B \\
\hline \multirow{7}{*}{$\mathrm{CoFe}_{1.5} \mathrm{Cr}_{0.5} \mathrm{O}_{4}$} & 0.203 & -0.025 & 48.05 & $A$ \\
\hline & 0.342 & -0.068 & 50.9 & $\mathrm{~B}_{3}$ \\
\hline & 0.260 & -0.093 & 49.73 & $\mathrm{~B}_{4}$ \\
\hline & 0.210 & 0.182 & 48.07 & $\mathrm{~B}_{5}$ \\
\hline & 0.296 & -0.335 & 45.63 & $\mathrm{~B}_{6}$ \\
\hline & 0.176 & -0.317 & 38.97 & $\mathrm{~B}_{7}$ \\
\hline & 0.254 & 0.427 & - & Paramagnetic \\
\hline \multirow[t]{8}{*}{$\mathrm{CoFeCrO}_{4}$} & 0.222 & 0.058 & 48.08 & $A$ \\
\hline & 0.344 & 0.028 & 50.02 & $\mathrm{~B}_{3}$ \\
\hline & 0.204 & -0.646 & 49.01 & $\mathrm{~B}_{4}$ \\
\hline & 0.362 & 0.504 & 48.63 & $\mathrm{~B}_{5}$ \\
\hline & 0.207 & -0.890 & 43.33 & $\mathrm{~B}_{6}$ \\
\hline & 0.241 & 0.183 & 39.34 & $\mathrm{~B}_{7}$ \\
\hline & 0.210 & -0.061 & 37.42 & $\mathrm{~B}_{8}$ \\
\hline & 0.263 & 0.414 & - & Paramagnetic \\
\hline $\mathrm{CoFe}_{0.5} \mathrm{Cr}_{1.5} \mathrm{O}_{4}$ & 0.263 & 0.401 & - & Paramagnetic \\
\hline Errors & \pm 0.002 & \pm 0.004 & \pm 0.15 & \\
\hline
\end{tabular}

Table 3. Magnetic parameters obtained from hysteresis loops of the chromium substituted cobalt ferrite $\left(\mathrm{CoFe}_{2-x} \mathrm{Cr}_{x} \mathrm{O}_{4}\right.$ where $0 \leq x \leq 2)$.

\begin{tabular}{ccccc}
\hline Sample & $T / \mathrm{K}$ & $\mathrm{M}_{\mathrm{s}} / \mathrm{emu} \mathrm{g}^{-1}$ & $\mathrm{Mr}_{\mathrm{r}} /$ emu g$^{-1}$ & $B_{\mathrm{c}} / \mathrm{T}$ \\
\hline $\mathrm{CoFe}_{2} \mathrm{O}_{4}$ & 5 & 82.34 & 63.61 & 0.519 \\
& 70 & 82.85 & 60.27 & 0.403 \\
& 120 & 83.22 & 55.46 & 0.345 \\
$\mathrm{CoFe}_{1.5} \mathrm{Cr}_{0.5} \mathrm{O}_{4}$ & 5 & 69.89 & 49.68 & 0.577 \\
& 70 & 67.96 & 46.34 & 0.444 \\
& 120 & 13.65 & 9.53 & 0.259 \\
$\mathrm{CoFe}_{0.5} \mathrm{Cr}_{1.5} \mathrm{O}_{4}$ & 5 & 42.38 & 30.13 & 0.461 \\
& 70 & 40.48 & 27.71 & 0.318 \\
& 120 & 36.41 & 23.86 & 0.259 \\
$\mathrm{CoFeCrO}_{4}$ & 5 & 20.47 & 30.13 & 0.461 \\
& 70 & 17.55 & 27.71 & 0.359 \\
& 120 & 13.65 & 23.86 & 0.304 \\
& 5 & 0.48 & 0.25 & 0.50 \\
$\mathrm{CoCr}_{2} \mathrm{O}_{4}$ & 70 & 0.69 & 0.43 & 0.02 \\
& 5 & & &
\end{tabular}



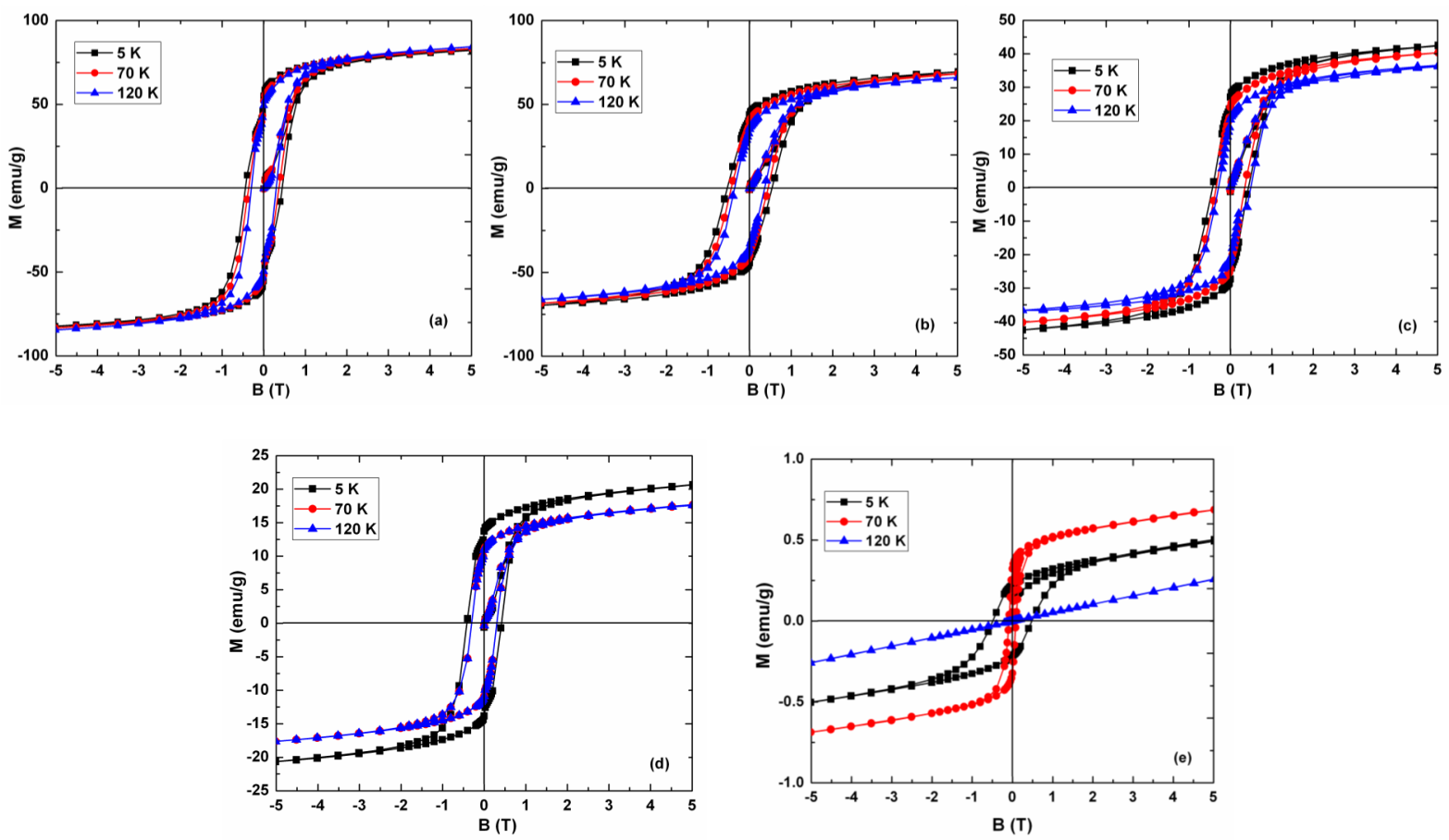

Figure 6. Magnetic hysteresis loops of chromium substituted cobalt ferrite $\left(\mathrm{CoFe}_{2-x} \mathrm{Cr}_{x} \mathrm{O}_{4}\right)$, where $x$ is: (a) 0 ; (b) 0.5 ; (c) 1 ; (d) 1.5 ; and (e) 2 , annealed at $700{ }^{\circ} \mathrm{C} / 1 \mathrm{~h}$.

turn decreases the domain wall energy. ${ }^{[38]}$ The same trend appears for all the three temperatures at which the magnetic measurements were made. However, the $B_{c}$ values of the samples which contain $\mathrm{Cr}^{3+}$ are slightly higher than $B_{\mathrm{c}}$ value corresponding to $\mathrm{CoFe}_{2} \mathrm{O}_{4}$; this may be due to the increase in the magnetic crystalline anisotropy. ${ }^{[39]}$

All these results show that the increase of $\mathrm{Cr}^{3+}$ content decreases the magnetization and the compounds are being converted into soft magnetic materials.

For $\mathrm{CoCr}_{2} \mathrm{O}_{4}$ sample a very clear hysteresis loop appears at $5 \mathrm{~K}$ which also is maintained at $70 \mathrm{~K}$. All the magnetic parameters values obtained for this sample are in good agreement with those reported until now on these polycrystalline compounds. ${ }^{[40]}$ At $120 \mathrm{~K}$ the ferrimagnetic magnetic order is changing, the sample becoming paramagnetic.

\section{CONCLUSION}

A series of chromium substituted cobalt ferrites $\left(\mathrm{CoFe}_{2-} \mathrm{Cr}_{x} \mathrm{O}_{4}\right.$, $0 \leq x \leq 2$ ) was synthesized through solution combustion method using glycine as fuel, named glycine-nitrates process (GNP). The XRD refinements indicate the crystallization of a cubic spinel structure; no other phases were identified in the samples. A particle refinement in correlation with chromium content $x$ was evidenced by SEM. Mössbauer spectroscopy revealed the site occupancy of $\mathrm{Fe}^{3+}$ and $\mathrm{Cr}^{3+}$ in the lattice and the preference of chromium ions for octahedral sites. The magnetic measurements evidenced a decrease in magnetization values with the increase of chromium content. At high chromium concentrations the samples become paramagnetic.

In summary, we can claim that the glycine-nitrate process is a fast, simple, low cost and reproducible method to obtain nanocrystalline chromium substituted cobalt ferrite.

Acknowledgment. Support of the European Union (ERDF) and Romanian Government, allowing the acquisition of the research infrastructure under POS-CCE O 2.2.1 project INFRANANOCHEM - Nr. 19/01.03.2009, is gratefully acknowledged. The work also benefits from the support of the "Materials Science and Advanced Characterization Methods" Programme of the "Ilie Murgulescu" Institute of Physical Chemistry, financed by the Romanian Academy. The author L. D. from the National Institute of Materials PhysicsRomania, acknowledges the support of the Core program PN09-450, as well as of the European Union and Romanian Government, under POS-CCE project CEUREMAVSU-Nr. 01/01.03.2009, allowing the acquisition of the research infrastructure. C. B. acknowledges support of the Sectorial Operational Programme Human Resource Development under the project: "Doctoral and postdoctoral programs support for the research competitiveness in sciences" number POSDRU/159/1.5/S/137750. 


\section{REFERENCES}

[1] N. Sanpo, C. C. Berndt, C. Wen, J. Wang, Acta Biomater. 2013, 9, 5830.

[2] D. Fino, N. Russo, G. Saracco, V. Specchia, Powder Technol. 2008, 180, 74.

[3] S. Amiri, H. Shokrollahi, Mater. Sci. Eng. C 2013, 33, 1.

[4] M. Ptak, M. Maczka, K. Hermanowicz, A. Pikul, J. Hanuza, J. Solid State Chem. 2013, 199, 295.

[5] S. Jauhar, S. Singhal, Ceram. Int. 2014, 40, 11845.

[6] Y. Köseoğlu, M. I. O. Oleiwi, R. Yilgin, A. N. Koçbay, Ceram. Int. 2012, 38, 6671.

[7] K. B. Modi, N. H. Vasoya, V. K. Lakhani, T. K. Pathak, P. M. G. Nambissan, Intern. J. Spectroscopy 2013, 272846.

[8] L. D. Tung, V. Kolesnichenko, D. Caruntu, N. H. Chou, C. J. O'Connor, L. Spinu, J. Appl. Phys. 2003, 93, 7486.

[9] C. Suchomski, C. Reitz, K. Brezesinski, C. Taveres de Sousa, M. Rohnke, K. limura, J. P. E. Araujo, T. Brezesinski, Chem. Mater. 2012, 24, 155.

[10] M. Vadivel, R. Ramesh Babu, K. Sethuraman, K. Ramamurthi, M. Arivanandhan, J. Mag. Mag. Mater. 2014, 362, 122.

[11] M. J. Iqbal, M. R. Siddiquah, J. Alloys Compd. 2008, 453, 513.

[12] I. Mindru, D. Gingasu, D. C. Culita, G. Marinescu, L. Patron in Dekker Encyclopedia of Nanoscience and Nanotechnology, Third Edition (Ed.: S. E. Lyshevski), CRC Press, New York, 2014, pp. 2176-2189.

[13] I. Mindru, D. Gingasu, L. Patron, G. Marinescu, J. M. Calderon-Moreno, L. Diamandescu, S. Preda, 0. Oprea, Ceram. Int. 2015, 41, 5318.

[14] P. P. Hankare, U. B. Sankpal, R. P. Patil, P. D. Lokhande, R. Sasikala, Mater. Sci. Eng. B 2011, 176, 103.

[15] Y. Köseoğlu, A. Baykal, F. Gözüak, and H. Kavas, Polyhedron 2009, 28, 2887.

[16] C. N Chinnasamy, M Senoue, B Jeyadevan, $O$. Perales-Perez, K Shinoda, and K Tohji, J. Colloid Interf. Sci. 2003, 263, 80.

[17] K. P. Chae, Y. B. Lee, J. G. Lee, S. H. Lee, J. Mag. Mag. Mater. 2000, 220, 59.

[18] D. Gingasu, I. Mindru, D. C. Culita, L. Patron, J. M. Calderon-Moreno, S. Preda, O. Oprea, P. Osiceanu, E. Morena Pineda, Mater. Res. Bull. 2014, 49, 151.

[19] D. Gingasu, I. Mindru, L. Patron, G. Marinescu, F. Tuna, S. Preda, J. M. Calderon-Moreno, C. Andronescu, Ceram. Int. 2012, 38, 6739.
[20] J. J. Kingsley, K. C. Patil, Mater. Lett. 1988, 6, 427.

[21] B. G. Toksha, S. E. Shirsath, M. L. Mane, S. M. Patange, S. S. Jadhav, K. M. Jadhav, J. Phys. Chem. C 2011, 115, 20905.

[22] J. C. Toniolo, M. D. Lima, A. S. Takimi, C. P. Bergmann, Mater. Res. Bull. 2005, 40, 561.

[23] C.-C. Hwang, J.-S. Tsai, T.-H. Huang, C.-H. Peng, S.-Y. Chen, J. Solid State Chem. 2005, 178, 382.

[24] D. Gingasu, I. Mindru, L. Patron, C. B. Cizmas, J. Alloys Compd. 2008, 460, 627.

[25] D. Gingasu, I. Mindru, G. Marinescu, L. Patron, C. Ghica, J. Alloys Compd. 2009, 481, 890.

[26] G. Marquez, V. Sagredo, C. Marquina, T. E. Torres, M. R. Ibarra, G. F. Goya, Rev. Mex. Fis. S 2012, 58, 138.

[27] S. Uday Bhasker, M. V. Ramana Reddy, J. Sol-Gel Sci. Technol. 2015, 73, 396.

[28] P. P. Hankare, U. B. Sankpal, R. P. Patil, I. S. Mulla, P. D. Lokhande, N. S. Gajbhiye, J. Alloys Compd. 2009, 485, 798.

[29] P. P. Hankare, V. T. Hader, U. B. Sankpal, R. P. Patil, A. V. Jadhav, I. S. Mulla, J. Mater. Sci.: Mater. Electron. 2011, 22, 1109.

[30] A. Sharma, O. P. Modi, G. K. Gupta, Adv. Appl. Sci. Res. 2012, 3, 2151.

[31] P. P. Hankare, V. T. Vader, N. M. Patil, S. D. Jadhav, U. B. Sankpal, M. R. Kadam, B. K. Chougule, N. S. Gajbhiye, Mater. Chem. Phys. 2009, 113, 233.

[32] M. Raghasudha, D. Ravinder, P. Veerasomaiah, Nanosci. \& Nanotech. 2013, 3, 105.

[33] N. N. Greenwood, T. C. Gibb, Mössbauer Spectroscopy, Chapman and Hall LTD, London, 1971, p. 266.

[34] G. A. Petit, D. W. Forester, Phys. Rev. B 1971, 4, 3912.

[35] G. S. N. Rao, B. Parvatheeswara Rao, H. H. Hamdeh, Procedia Materials Science 2014, 6, 1511.

[36] M. K. Fayek, F. M. Sayed Ahmed, S. S Ata-Allah, M. K. Elnimer, M. F. Mostafa, J. Mat. Sci. 1992, 27, 4813.

[37] L. Zhao, H. Yang, X. Zhao, L. Yu, Y. Cui, S. Feng, Mat. Lett. 2006, 60, 1.

[38] I. H. Gul, A. Z. Abbasi, F. Amin, M. Anis-ur-Rehman, A. Maqsood, J. Magn. Magn. Mater. 2007, 311, 494.

[39] S. E. Shirsath, S. S. Jadhav, B.G. Toksha, S. M. Patange, K. M. Jadhav, J. Appl. Phys. 2011, 110, 013914.

[40] I. Mindru, D. Gingasu, G. Marinescu, L. Patron, J. M. Calderon-Moreno, C. Bartha, C. Andronescu, Alina Crisan, Ceram. Int. 2014, 40, 15249. 